\title{
CONVERSION OF HYDROCARBON FUEL IN THERMAL PROTECTION REACTORS OF HYPERSONIC AIRCRAFT
}

\author{
A. L. Kuranov ${ }^{1}$, A. M. Mikhaylov ${ }^{1}$, \\ and A. V. Korabelnikov ${ }^{2}$ \\ ${ }^{1}$ Hypersonic Systems Research Enterprise of Leninetz HC \\ 212 Moskovski Prosp., St. Peterburg, Russia \\ ${ }^{2}$ St. Petersburg State Polytechnical University \\ 29 Polytechnicheskaya Str., St. Petersburg, Russia
}

\begin{abstract}
Thermal protection of heat-stressed surfaces of a high-speed vehicle flying in dense layers of atmosphere is one of the topical issues. Not of a less importance is also the problem of hydrocarbon fuel combustion in a supersonic air flow. In the concept under development, it is supposed that in the most high-stressed parts of airframe and engine, catalytic thermochemical reactors will be installed, wherein highly endothermic processes of steam conversion of hydrocarbon fuel take place. Simultaneously with heat absorption, hydrogen generation will occur in the reactors. This paper presents the results of a study of conversion of hydrocarbon fuel in a slit reactor.
\end{abstract}

\section{INTRODUCTION}

Endothermic reactions as a method of cooling are considered by many researchers due to the necessity of removal and recovery of large heat fluxes. The use of different types of hydrocarbons as reagents allows, except removal of heat by the endothermic effect of the reaction, to obtain a hydrogen-containing fuel with better energy characteristics. The use of hydrocarbon fuel conversion for cooling heat-stressed areas of high-speed vehicles and organization of their burning in supersonic air flow have been considered by the experts from the 1960s. It is well known that the major drawback of hydrocarbon fuels resides in considerable $\left(t_{d} \sim 10 \mathrm{~ms}\right)$, as compared to hydrogen $\left(\tau_{d} \sim 0.1 \mathrm{~ms}\right)$, times of ignition delay which leads to the necessity of long combustion chambers. However, mixing of hydrogen produced in thyristor controlled reactor (TCR) with basic mass of kerosene results in decrease of ignition time for flammable mixture [1]. Thus, the considered concept solves both designated tasks. 


\section{EXPERIMENTATION}

Based on the application, it was decided to use flat TCR of 571-millimeter length, 60-millimeter width, and 4-millimeter thickness as a model of thermal protection element which brings it closer to the actual required shape. The particular properties of the selected heat source (EDP-109M; electric-arc plasmatron) necessitate thermal protection cover over the central channel, through which nitrogenous plasma jet, obtained in plasmotron, passes. The walls forming the channel are protectable. Geometrically, it was decided to make the central channel of a flat shape of a width exceeding the height significantly. Such a design provided an opportunity not to protect side walls, sufficiently distant from the core of the flow. Besides, as a result of flow flattening, in the vicinity of the central vertical section, in the two-dimensional (2D) channel, heat exchange is intensified. At the entrance to the TCR, a mixer with tangential in-feed of components was placed for ensuring their mixing and distribution between the upper and the lower channels.

The framework of a model reactor is made of the XH78T alloy with the onset scaling temperature in air making $1150{ }^{\circ} \mathrm{C}$ and the maximum recommended operating temperature for a long period (up to $10000 \mathrm{~h}$ ) corresponds to $1100{ }^{\circ} \mathrm{C}$. This alloy is used for the manufacture of flame tubes of high-temperature combustion chambers of turbojet engines operating at $1000-1100{ }^{\circ} \mathrm{C}$. Another very important advantage of this alloy is the composition of its components which is very close to that of nichrome $\mathrm{X} 20 \mathrm{H} 80$ previously used as catalytic coatings. This allows, after special treatment of the reactor internal surfaces, carrying out steam conversion of hydrocarbons directly on its wall.

To increase the degree of conversion of hydrocarbon fuels, special wireframe catalysts have been made. Such a catalyst is a compressed nichrome wire etched to increase specific surface area and activated in an oxygen atmosphere in a muffle furnace. A more detailed description of the experimental reactor can be seen in $[2,3]$.

Experimentation was designed to determine the modes of TCR of thermal protection with the maximum degree of conversion subject to the removal of significant heat fluxes. Apart from that, applicability of the selected material for TCR framework has been checked and operation of the new catalysts has been analyzed.

The input parameters of the experiment were: the flow of steam, methane flow, nitrogen flow in the plasmatron, the temperature of the mixture of water vapor and methane at the reactor inlet, and plasmatron power. The main output parameters directly measured were: temperature of the cooled wall measured at six points and chemical composition of the mixture taken up in the sampling points. Based upon measured values of the input and output parameters, it is possible to obtain heat flux rate, mixture flow rate, and conversion degree of methane. 


\section{Experimental Results}

A total of 4 sustained experiments have been carried out during which 11 steadystate regimes were investigated. The first experiment was carried out without wireframe catalyst in TCR. One steady-state mode was studied. Ratio of steam $\left(\mathrm{GH}_{2} \mathrm{O}\right)$ to methane $\left(\mathrm{GCH}_{4}\right)$ consumption was taken in excess of the stoichiometric one $\left(\mathrm{H}_{2} \mathrm{O} / \mathrm{CH}_{4} \sim 2: 1\right)$. Parameter values of steady-state regimes are presented in Table 1.

Due to the fact that plasmotron power was rather insufficient $(25.1 \mathrm{~kW})$ under significant consumption of the components $\left(\mathrm{GH}_{2} \mathrm{O}-0.27 \mathrm{~g} / \mathrm{s} ; \mathrm{GCH}_{4}-\right.$ $0.13 \mathrm{~g} / \mathrm{s}$ ), temperature of the walls remained low leading to a low-level conversion degree without catalysts (0.43). The second and subsequent experiments were carried out with wireframe catalysts in TCR.

The second experiment resulted in successful accomplishment of three stationary modes. The component ratio at the reactor inlet was maintained at $\mathrm{GH}_{2} \mathrm{O} / \mathrm{GCH}_{4} \sim 2: 1$. The first was a straight-through, with a significant subcooled wall $\left(T_{w}<650{ }^{\circ} \mathrm{C}\right)$. Because the wall temperatures are below the ones at which the conversion rate of the steam is considerable, it can be said that this mode does not provide steam conversion. During the second mode, the plasmotron power was raised to $39.5 \mathrm{~kW}$. The wall temperature has reached the

Table 1 Stationary modes of the first experiment

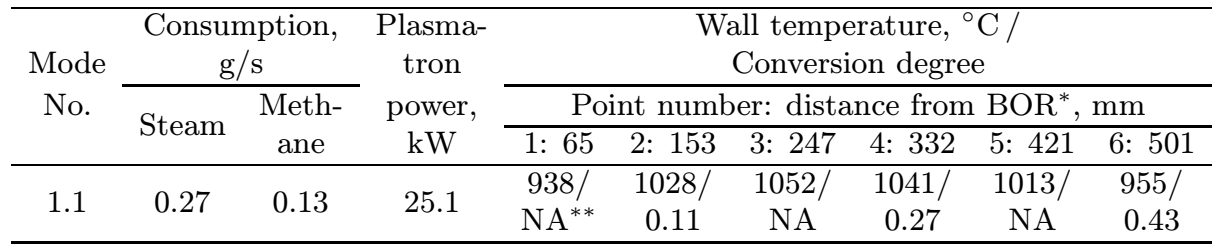

${ }^{*} \mathrm{BOR}$ - beginning of reactor.

${ }^{* *} \mathrm{NA}$ - no data available.

Table 2 Stationary modes of the second experiment

\begin{tabular}{|c|c|c|c|c|c|c|c|c|c|}
\hline \multirow{3}{*}{$\begin{array}{l}\text { Mode } \\
\text { No. }\end{array}$} & \multicolumn{2}{|c|}{$\begin{array}{c}\text { Consumption, } \\
\mathrm{g} / \mathrm{s}\end{array}$} & \multirow{3}{*}{$\begin{array}{c}\text { Plasma- } \\
\text { tron } \\
\text { power, } \\
\text { kW }\end{array}$} & \multicolumn{6}{|c|}{ Wall temperature, ${ }^{\circ} \mathrm{C}$} \\
\hline & Water & Meth- & & \multicolumn{6}{|c|}{ Point number: distance from BOR, mm } \\
\hline & steam & ane & & 1: 65 & 2: 153 & 3: 247 & 4: 332 & 5: 421 & 6: 501 \\
\hline 2.1 & 0.3 & 0.13 & 14.8 & 605 & 614 & 587 & 555 & 529 & 503 \\
\hline 2.2 & 0.29 & 0.14 & 39.5 & 996 & 1049 & 1027 & 989 & 939 & 892 \\
\hline 2.3 & 1.0 & 0.51 & 49.8 & 1206 & 1280 & 1272 & 1259 & 1242 & 1192 \\
\hline
\end{tabular}


value of $1000{ }^{\circ} \mathrm{C}$. Comparing this mode with the one of the first experiment, it can be said that it is possible to constrain temperature at the same level under identical consumption and plasmatron power above 1.6 times. This points to significant increase in the rate of reaction - thanks to the catalyst. In the third mode, plasmatron power was further raised to $49.8 \mathrm{~kW}$ and, besides, consumption of methane and water vapor has been raised too. Furthermore, the walls temperature has reached $1280^{\circ} \mathrm{C}$. Table 2 shows the values of the parameters in the stationary mode.

The third experiment resulted in successful accomplishment of the two stationary modes. The ratio of components was also maintained at the level $\mathrm{GH}_{2} \mathrm{O} / \mathrm{GCH}_{4} \sim 2: 1$, while the second mode differed from the first one in

Table 3 Stationary modes of the third experiment

\begin{tabular}{|c|c|c|c|c|c|c|c|c|c|}
\hline \multirow{3}{*}{$\begin{array}{l}\text { Mode } \\
\text { No. }\end{array}$} & \multicolumn{2}{|c|}{$\begin{array}{c}\text { Consumption, } \\
\mathrm{g} / \mathrm{s}\end{array}$} & \multirow{3}{*}{$\begin{array}{c}\text { Plasma- } \\
\text { tron } \\
\text { power, } \\
\mathrm{kW}\end{array}$} & \multicolumn{6}{|c|}{ Wall temperature, ${ }^{\circ} \mathrm{C}$} \\
\hline & \multirow{2}{*}{$\begin{array}{l}\text { Water } \\
\text { steam }\end{array}$} & \multirow{2}{*}{$\begin{array}{l}\text { Meth- } \\
\text { ane }\end{array}$} & & \multicolumn{6}{|c|}{$\begin{array}{l}\text { Point number: distance from BOR, } \mathrm{mm} \\
\end{array}$} \\
\hline & & & & $1: 65$ & $2: 153$ & 3: 247 & 4: 332 & $5: 421$ & 6: 501 \\
\hline 3.1 & 0.26 & 0.12 & 16.3 & 717 & 756 & 760 & 749 & 739 & 710 \\
\hline 3.2 & 0.26 & 0.13 & 29.9 & 1047 & 1100 & 1081 & 1065 & 1047 & 1007 \\
\hline
\end{tabular}

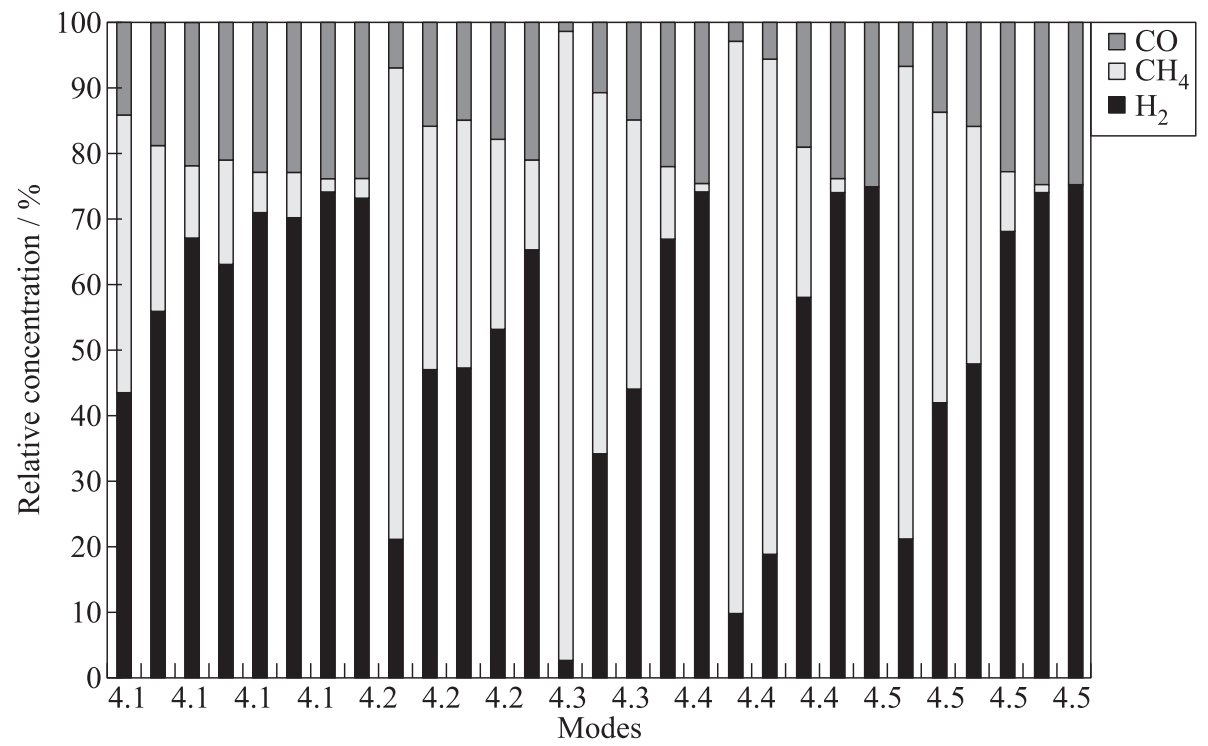

Figure 1 Relative gas concentrations in the fourth experiment 
Table 4 Stationary modes of the fourth experiment

\begin{tabular}{|c|c|c|c|c|c|c|c|c|c|}
\hline \multirow{3}{*}{$\begin{array}{l}\text { Mode } \\
\text { No. }\end{array}$} & \multicolumn{2}{|c|}{$\begin{array}{c}\text { Consumption, } \\
\mathrm{g} / \mathrm{s}\end{array}$} & \multirow{3}{*}{$\begin{array}{c}\text { Plasma- } \\
\text { tron } \\
\text { power, } \\
\mathrm{kW}\end{array}$} & \multicolumn{6}{|c|}{$\begin{array}{c}\text { Wall temperature, }{ }^{\circ} \mathrm{C} / \\
\text { Conversion degree }\end{array}$} \\
\hline & \multirow{2}{*}{$\begin{array}{l}\text { Water } \\
\text { steam }\end{array}$} & \multirow{2}{*}{$\begin{array}{l}\text { Meth- } \\
\text { ane }\end{array}$} & & \multicolumn{6}{|c|}{ Point number: distance from $\mathrm{BOR}, \mathrm{mm}$} \\
\hline & & & & $1: 65$ & 2: 153 & $3: 247$ & 4: 332 & 5: 421 & 6: 501 \\
\hline \multirow{2}{*}{4.1} & \multirow{2}{*}{0.26} & \multirow{2}{*}{0.13} & \multirow{2}{*}{26.1} & $945 /$ & $1015 /$ & $1010 /$ & $997 /$ & $984 /$ & $946 /$ \\
\hline & & & & NA & 0.58 & 0.75 & 0.89 & 0.94 & 0.98 \\
\hline \multirow{2}{*}{4.2} & \multirow{2}{*}{0.44} & \multirow{2}{*}{0.33} & \multirow{2}{*}{30.1} & $947 /$ & $1038 /$ & $1045 /$ & $1035 /$ & $1019 /$ & $976 /$ \\
\hline & & & & NA & 0.28 & 0.62 & NA & 0.71 & 0.86 \\
\hline \multirow{2}{*}{4.3} & \multirow{2}{*}{0.44} & \multirow{2}{*}{0.54} & \multirow{2}{*}{30} & $910 /$ & $1015 /$ & $1036 /$ & $1030 /$ & $1015 /$ & $976 /$ \\
\hline & & & & NA & 0.04 & 0.45 & 0.59 & 0.89 & 0.99 \\
\hline \multirow{2}{*}{4.4} & \multirow{2}{*}{0.45} & \multirow{2}{*}{0.53} & \multirow{2}{*}{51} & $1146 /$ & $1195 /$ & $1163 /$ & $1147 /$ & $1112 /$ & $1069 /$ \\
\hline & & & & NA & 0.13 & 0.25 & 0.77 & 0.98 & 1.00 \\
\hline \multirow[t]{2}{*}{4.5} & \multirow[t]{2}{*}{0.45} & \multirow[t]{2}{*}{0.54} & \multirow[t]{2}{*}{60.2} & $1266 /$ & $1290 /$ & $1246 /$ & $1225 /$ & $1193 /$ & 1141/ \\
\hline & & & & & 0.28 & 0.56 & & 0.91 & \\
\hline
\end{tabular}

plasmatron power rise and insignificant buildup of methane consumption. Table 3 presents the values of the parameters in the stationary modes of the third experiment.

During fourth experiment, 5 stationary modes have been successfully accomplished. In the course of the first one, the consumption was maintained at $\mathrm{GH}_{2} \mathrm{O} / \mathrm{GCH}_{4} \sim 2: 1$ and during the second $-\mathrm{GH}_{2} \mathrm{O} / \mathrm{GCH}_{4} \sim 4: 3-$ close to the stoichiometric ratio. Further on, three modes were investigated with the ratio $\mathrm{GH}_{2} \mathrm{O} / \mathrm{GCH}_{4} \sim 9$ : 11, i. e., with a significant deviation from stoichiometry in the area of methane excess. During the experiment, the analysis of the chemical composition has been carried out (Fig. 1). Concentrations of methane $\left(\mathrm{CH}_{4}\right)$ and the major products of the reaction - hydrogen $\left(\mathrm{H}_{2}\right)$ and carbon monooxide $(\mathrm{CO})$ - for each steady state have been subsequently determined lengthways of the reactor.

Table 4 presents the values of major parameters corresponding to the stationary modes of the fourth experiment. As can be seen, the modes were investigated with high plasmatron power and increased consumption where high-temperature values have been obtained. It is also worth noting the high degree of conversion in all modes.

\section{MATHEMATICAL MODEL}

The experimental data obtained are insufficient for a description of the heat-andmass transfer processes under investigation since not all physical values could be measured in the experiments. To determine such values, it is necessary to use 
the tools of mathematical modeling. Based on the data obtained in the course of the experiments, it is possible to create a model that describes the relationship of the target values under conducted experiments.

First of all, it is necessary to determine the distribution of the value of specific heat flux issuing from the nitrogen plasma and absorbing in TCR. It is the principal criterion for the applicability of steam conversion in the elements of the active thermal protection.

Next, one needs to evaluate the relative efficiency of the TCR (with catalytic filling) operation in the implemented modes. For experiments in which there were no data on gas composition, it was necessary to calculate the distribution of the reacting mixture. To determine all these parameters, a model was developed which consists of two parts.

The first part of the central channel model describes the interaction of the nitrogen plasma jet and the TCR's metal wall with the known measured temperature; here, the distribution of the specific heat flux is determined. The second part of the channel model describes the processes that occur directly inside the TCR, namely, heating and chemical transformations of the component flow. The rate and composition of the reacting mixture are determined from the second part of the model, the calculation is based on the determined distribution of the specific heat flux. Mathematical calculations were carried out in the environment of finite-difference simulation - Comsol 4.3a. The module "Conjugate Heat Transfer" describing the conductive and convective heat transfer in media and solids moving according to laminar laws was used in the first part of the experimental model. In the second part of the model the modules "Darcy's Law," "Heat Transfer in Fluids," and "Transport of Concentrated Species" have been used. These modules together describe hear transfer and thermochemical processes for multicomponent mixture flowing in a porous medium.

\subsection{The Model of the Central Channel}

Geometrically, the model of the central channel is a channel $A B C D 571 \mathrm{~mm}$ long and $20 \mathrm{~mm}$ wide with walls having a thickness of $4 \mathrm{~mm}$ (Fig. 2). The heated in plasmatron nitrogen travels into the channel over the edge $A B$. While passing through the central channel, nitrogen heats the wall.

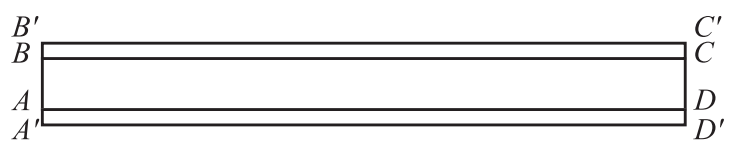

Figure 2 The geometrical representation of the central channel model 
Flow and heat transfer in the central channel $A B C D$ are described by a set of equations:

$$
\begin{aligned}
\rho \frac{\partial \vec{u}}{\partial t}+\rho(\vec{u} \times \nabla) \vec{u} & =\nabla \times\left(-\rho \vec{I}+\mu\left(\nabla \vec{u}+(\nabla \vec{u})^{\mathrm{T}}\right)\right)+\vec{F} ; \\
\rho \nabla \times \vec{u} & =0 ; \\
\rho C_{p} \frac{\partial T}{\partial t}+\rho C_{p} \vec{u} \times \nabla T & =\nabla \times(k \nabla T)+Q
\end{aligned}
$$

where $\rho$ is the density, $\mathrm{kg} / \mathrm{m}^{3} ; \vec{u}$ is the velocity vector, $\mathrm{m} / \mathrm{s} ; t$ is the time, $\mathrm{s} ; \vec{I}$ is the identification matrix; $\mu$ is the dynamic viscosity, $\mathrm{Pa} \cdot \mathrm{s} ; \vec{F}$ is the pressure gradient, $\mathrm{Pa} / \mathrm{m} ; C_{p}$ is the specific heat at constant pressure, $\mathrm{J} /(\mathrm{K} \cdot \mathrm{kg}) ; T$ is the temperature, $\mathrm{K} ; k$ is the thermal conductivity, $\mathrm{W} /(\mathrm{m} \cdot \mathrm{K})$; and $Q$ is the heat flux, W.

Boundary conditions in $B C$ and $A D$ are $\vec{u}=0$.

Boundary conditions in $A B$ determine nitrogen flow rate $m, \mathrm{~g} / \mathrm{s}$ :

$$
-d_{b c} \int_{\partial \Omega} \rho(\vec{u} \times \vec{n}) d S=m
$$

and concurrent heat flux $q_{0}, \mathrm{~W}$ :

$$
-\vec{n} \times(-k \nabla T)=\left(-q_{0}(\vec{u} \times \vec{n}) \frac{\int l}{\int|\vec{u} \times \vec{n}|}\right)+\rho\left(\Delta h_{\text {in }}-\Delta h_{\infty}\right) \vec{u} \times \vec{n}
$$

where

$$
\Delta h_{\mathrm{in}}-\Delta h_{\infty}=\int_{T_{\infty}}^{T_{\mathrm{in}}} C_{p} d T+\int_{P_{\infty}}^{p T_{a}} \frac{1}{\rho}\left(1+\left.\frac{T}{\rho}\left(\frac{\partial \rho}{\partial T}\right)\right|_{p}\right) d p .
$$

Boundary conditions in $C D$ determine free outflow of nitrogen into the medium with pressure $p_{0}=100 \mathrm{kPa}$ :

$$
p=p_{0} ; \quad\left(\mu\left(\nabla \vec{u}+(\nabla \vec{u})^{\mathrm{T}}\right)-\frac{2}{3} \mu(\nabla \times \vec{u}) \vec{l}\right) \times \vec{n}=0 .
$$

Besides, the heat output in $C D$ is determined only as nitrogen heat:

$$
-\vec{n} \times(-k \nabla T)=0 .
$$

Heat transfer to the walls $A A^{\prime} D^{\prime} D$ and $B B^{\prime} C^{\prime} C$ is described by heat-transfer equation:

$$
\rho C_{p} \frac{\partial T}{\partial t}+\rho C_{p} \vec{u} \times \nabla T=\nabla \times(k \nabla T)+Q .
$$


Boundary conditions for the walls are: thermal insulation of the walls $A A^{\prime}$, $B B^{\prime}, C C^{\prime}$, and $D D^{\prime}:-\vec{n} \times(-k \nabla T)=0$, and for the $A^{\prime} D^{\prime}$ and $B^{\prime} C^{\prime}$, the temperature corresponding to the wall temperature at the test of full-scale model, determined by interpolation of the experimental data: $T=T_{0}(t, x)$.

\subsection{The Model of TCR Channel}

In the $2 \mathrm{D}$ approximation, TCR is a rectangular channel (Fig. 3) in which from cross section $E F$ to the cross section $G H$, a reactive mixture flows. The channel is filled with porous catalyst. The mixture composition is changing with depleting of the initial components. If at the input it consists of methane and water steam, the main components of the output are carbon monoxide and hydrogen. The $F G$ wall is heat-insulated and through the wall $E H$, the temperature of which corresponds to the wall temperature of the full-scale model of the experiment, heat flux, determined by the first part of the mathematical model of the experiment, passes.

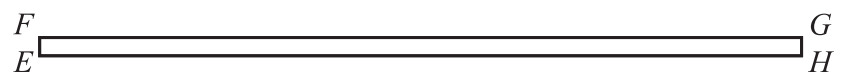

Figure 3 Geometrical representation of the TCR model

The processes occurring in the reactor are described by the following system of equations:

$$
\begin{aligned}
\frac{\partial}{\partial t}\left(\rho \varepsilon_{p}\right)+\nabla(\rho \vec{u}) & =Q_{m} \\
\rho C_{p} \frac{\partial T}{\partial t}+\rho C_{p} \vec{u} \times \nabla T & =\nabla \times(k \nabla T)+Q ; \\
\rho \frac{\partial \omega_{i}}{\partial t}+\nabla \times \vec{j}_{i}+\rho(\vec{u} \times \nabla) \omega_{i} & =R_{i}
\end{aligned}
$$

where

$$
\begin{gathered}
\vec{u}=-\frac{K}{\mu} \nabla p ; \quad \vec{J}_{i}=-\left(\rho D_{i}^{m} \nabla \omega_{i}+\rho \omega_{i} D_{i}^{m} \frac{\nabla M_{n}}{M_{n}}+D_{i}^{T} \frac{\nabla T}{t}\right) ; \\
\vec{N}_{i}=\vec{J}_{i}+\rho \vec{u} \omega_{i} ; \quad D_{i}^{m}=\left(1-\omega_{i}\right)\left(\sum_{k \neq i} \frac{x_{k}}{D_{i k}}\right)^{-1} ; \quad M_{n}=\left(\sum_{i} \frac{\omega_{i}}{M_{i}}\right)^{-1} ;
\end{gathered}
$$

$\varepsilon_{p}$ is the porosity index; $Q_{m}$ is the heat from reaction, $\mathrm{W} ; K$ is the hydraulic conductivity, $\mathrm{m} / \mathrm{s} ; \omega_{i}$ is the mass fraction of component $i ; \vec{J}_{i}$ is the source power of the $i$ th component, $\mathrm{kg} / \mathrm{s} ; R_{i}$ is the mass reaction rate, $\mathrm{kg} /\left(\mathrm{m}^{3} \cdot \mathrm{s}\right) ; D_{i k}$ is the 
coefficient of mutual diffusion of the $i$ th and $k$ th components, $\mathrm{m}^{2} / \mathrm{s} ; D_{i}^{T}$ is the thermal diffusion coefficient, $\mathrm{kg} /(\mathrm{m} \cdot \mathrm{s}) ; x_{k}$ is the volume fraction of the $k$ th component; and $M_{i}$ is the molar mass of the $i$ th component, $\mathrm{g} / \mathrm{mol}$.

Equation (1) is the equation of Darcy's law; Eq. (2) is the heat-transfer equation; and Eq. (3) is the continuity law for each mixture component.

The boundary conditions on $E H$ are described by

$$
-\vec{n} \times \rho \vec{u}=0 ; T=T_{w} ;-\vec{n} \times \vec{N}_{1}=0
$$

where $T_{w}$ is the wall temperature.

The boundary conditions on $E F$ are described by

$$
-\vec{n} \times \rho \vec{u}=N_{0} ; T=T_{\mathrm{im}} ; \omega_{i}=\omega_{0 i}
$$

where $T_{\mathrm{im}}$ is the temperature of the input mixture; $N_{0}$ is the nitrogen consumption; and $\omega_{0 i}$ is the initial mass content of components.

The boundary conditions on $F G$ are described by

$$
-\vec{n} \times \rho \vec{u}=0 ;-\vec{n} \times(-k \nabla T)=0 ;-\vec{n} \times \vec{N}_{i}=0 .
$$

The boundary conditions on $G H$ are described by

$$
p=p_{0} ;-\vec{n} \times(-k \nabla T)=0 ;-\vec{n} \times \rho D_{i}^{m} \nabla \omega=0
$$

where $p_{0}$ is the output pressure.

For performing calculations, the computational mesh was used with variable cell sizes dictated by the intensity of parameter variation. The initial condition for the calculation was chosen to be the state of the full-scale model before plasmatron startup. The calculation of each step was carried out using MUMPS technique (MUltifrontal Massively Parallel sparse direct Solver) with nonlinear Newtonian steps. Time steps were carried out by the method of reverse differentiation formulas.

For calculation purposes, experimental findings I, II, and III have been used, namely, the readings from sensors of wall temperature, current and voltage sensors of plasmatron, temperature and cooling water consumption, nitrogen and methane consumption, readings of the measuring complex for water steam, and mixture temperature at the TCR inlet. Temporal functional relationship was determined for all parameters by the method of spline interpolation of sensor readings. Distribution of temperatures alongside the reactor on the basis of the wall-temperature sensor readings was also determined.

\section{CALCULATION RESULTS}

As a result of calculations, temporal dependencies of temperature, vector field of the heat flux, mixture composition, and vector field of the velocity distributions have been obtained. 
Table 5 Absorbed heat fluxes

\begin{tabular}{ccrrrrr}
\hline $\begin{array}{c}\text { Time, } \\
\mathrm{s}\end{array}$ & $\begin{array}{c}Q_{c 1}, \\
\mathrm{~kW} / \mathrm{m}^{2}\end{array}$ & $\begin{array}{c}Q_{c 2}, \\
\mathrm{~kW} / \mathrm{m}^{2}\end{array}$ & $\begin{array}{c}Q_{c 3}, \\
\mathrm{~kW} / \mathrm{m}^{2}\end{array}$ & $\begin{array}{c}Q_{c 4}, \\
\mathrm{~kW} / \mathrm{m}^{2}\end{array}$ & $\begin{array}{r}Q_{c 5}, \\
\mathrm{~kW} / \mathrm{m}^{2}\end{array}$ & $\begin{array}{r}Q_{c 6}, \\
\mathrm{~kW} / \mathrm{m}^{2}\end{array}$ \\
\hline \multicolumn{7}{c}{ The model of the central channel } \\
\hline 2700 & 18.2 & 9.4 & 6.9 & 6.4 & 6.1 & 6.5 \\
3800 & 30.0 & 17.0 & 11.0 & 10.8 & 10.9 & 11.5 \\
4300 & 31.4 & 17.2 & 11.4 & 11.0 & 10.9 & 11.2 \\
4750 & 53.6 & 38.7 & 30.2 & 27.7 & 27.1 & 28.4 \\
4825 & 69.9 & 40.6 & 29.3 & 27.3 & 26.5 & 25.5 \\
\hline \multicolumn{7}{c}{ TCR model } \\
\hline 2700 & 20.1 & 10.7 & 7.8 & 7.2 & 6.6 & 6.8 \\
3800 & 32.4 & 19.2 & 12.5 & 12.2 & 12.2 & 12.7 \\
4300 & 33.9 & 19.5 & 13.2 & 12.6 & 12.4 & 12.7 \\
4750 & 58.0 & 42.1 & 32.6 & 29.8 & 28.8 & 29.9 \\
4825 & 74.7 & 44.3 & 31.9 & 29.5 & 28.3 & 27.1 \\
\hline \multicolumn{7}{c}{}
\end{tabular}

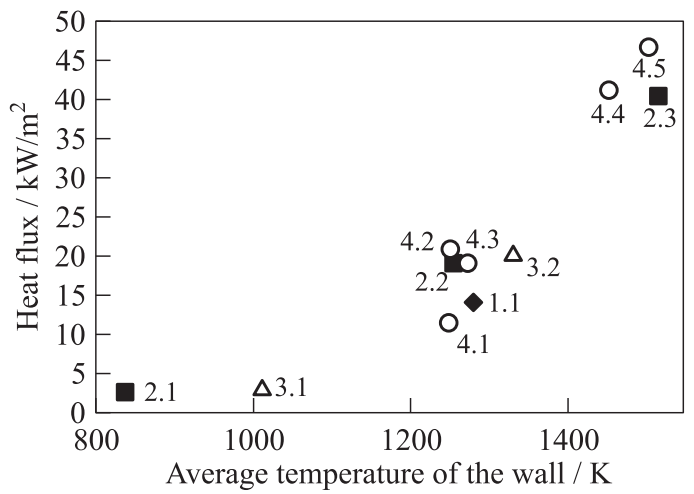

Figure 4 The dependence of the average heat flux on the average wall temperature in different modes (marked by numbers)

As can be seen from Table 5, the calculations with two models brought almost similar results. It is worth noting that at relatively small values of heat fluxes, their magnitude obtained by the calculation with TCR model is most different from the one calculated with the model of the central channel. Under the test conditions, the magnitude of the heat flux was determined by the temperature of the wall heated by plasmatron. This relationship is shown in Fig. 4.

An important parameter is the specific heat absorption. The dependence of the specific heat absorption on the specific heat flux is presented in Fig. 5. As can be seen, some experiments resulted in getting the values of specific heat absorption above $3 \mathrm{MJ} / \mathrm{kg}$. However, in several experiments with a high degree 


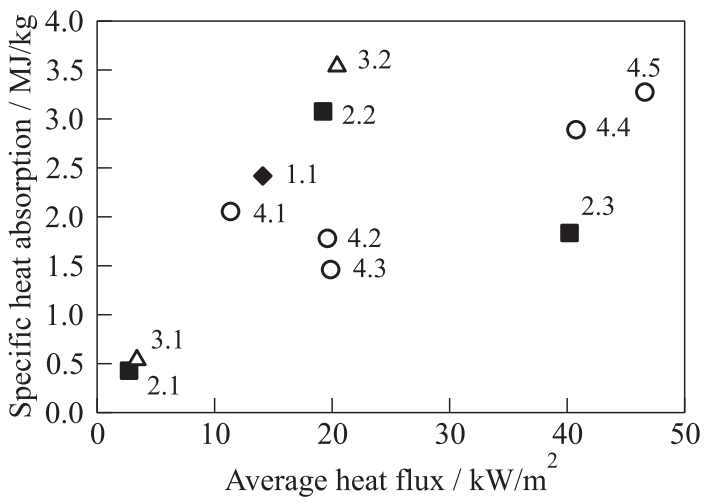

Figure 5 Dependence of specific heat absorption on the average heat flux in different modes (marked by numbers)

of conversion, the specific heat absorption was less than $2 \mathrm{MJ} / \mathrm{kg}$. Since the theoretical maximum value of specific heat absorption for the mixture of methane and water with a stoichiometric component ratio makes $\sim 8-10 \mathrm{MJ} / \mathrm{kg}$, including the chemical cooling capacity of $6 \mathrm{MJ} / \mathrm{kg}$, it is worth to mention that the mixture absorbs only from $17 \%$ to $63 \%$ of the total cooling capacity in modes with a high degree of conversion directly from the cooled wall.

Table 6 compares experimental and theoretical values of the specific heat absorption. As can be seen, the cooling efficiency (to cool the walls) in different

Table 6 Specific heat absorption and efficiency of cooling capacity

\begin{tabular}{cccc}
\hline \multirow{2}{*}{ Mode } & \multicolumn{2}{c}{$\begin{array}{c}\text { Specific heat } \\
\text { absorption, MJ/kg }\end{array}$} & $\begin{array}{c}\text { Cooling efficiency } \\
\text { inside TCR, } \\
\%\end{array}$ \\
\cline { 2 - 3 } & Experiment & Theory & 44 \\
\hline 1.1 & 2.42 & 5.53 & 8 \\
2.1 & 0.42 & 5.14 & 55 \\
2.2 & 3.02 & 5.54 & 32 \\
2.3 & 1.82 & 5.74 & 11 \\
3.1 & 0.57 & 5.37 & 63 \\
3.2 & 3.56 & 5.67 & 34 \\
4.1 & 2.04 & 5.96 & 24 \\
4.2 & 1.74 & 7.39 & 17 \\
4.3 & 1.45 & 8.81 & 32 \\
4.4 & 2.88 & 9.01 & 35 \\
4.5 & 3.25 & 9.19 & \\
\hline
\end{tabular}


experiments varies greatly, though the conversion degree remains high. This is due to the fact that during the preparation and mixing, the components absorb sufficient heat to ensure a high degree of conversion, and the heat from the wall, though contributing significantly to the heat balance, does not affect the conversion.

\section{CONCLUDING REMARKS}

The selected material was under treatment for more than 100 min subjected to high temperatures exceeding $1000{ }^{\circ} \mathrm{C}$. Subsequently neither mechanical changes were spotted on it, nor traces of scale formation observed. The applied catalyst made it possible not only to markedly increase the conversion degree but also to improve thermal protection. In the experiments carried out with a fixed catalyst, high values of conversion degree for methane were obtained. A wide range of experimental parameters for assessing the performance of the reactor as a part of thermal protection in the modes with low heat fluxes and high degrees of conversion has been covered in this paper.

\section{REFERENCES}

1. Kuranov, A. L., A. V. Korabelnikov, and A. M. Mikhailov. 2012. Thermal protection and hydrogen production on board of the hypersonic vehicle. 18th AIAA/3AF Space Planes and Hypersonic Systems and Technologies Conference (International). Tours, France.

2. Kuranov, A. L., A. V. Korabelnikov, and A. M. Mikhailov. 2012. Experimental study of steam reforming of methane in the thermochemical reactor. Symposium (International) on Thermochemical Processes in Plasma Aerodynamics. St. Petersburg, Russia.

3. Kuranov, A. L., A. V. Korabelnikov, and A. M. Mikhailov. 2012. Application of steam conversion of hydrocarbonic fuel in hypersonic aircraft power installations. Conference (International) on the Methods of Aerophysical Research (ICMAR). Kazan, Russia. 